Article

\title{
Kaempferol Induces G2/M Cell Cycle Arrest via Checkpoint Kinase 2 and Promotes Apoptosis via Death Receptors in Human Ovarian Carcinoma A2780/CP70 Cells
}

\author{
Ying Gao ${ }^{1}$, Junfeng Yin ${ }^{1}$, Gary O. Rankin ${ }^{2}$ and Yi Charlie Chen ${ }^{3, *}$ (iD \\ 1 Tea Research Institute Chinese Academy of Agricultural Sciences, Ministry of Agriculture, \\ Hangzhou 310008, China; yinggao@tricaas.com (Y.G.); yinjf@tricaas.com (J.Y.) \\ 2 Department of Biomedical Sciences, Joan C. Edwards School of Medicine, Marshall University, \\ Huntington, WV 25755, USA; rankin@marshall.edu \\ 3 College of Science, Technology and Mathematics, Alderson Broaddus University, Philippi, WV 26416, USA \\ * Correspondence: chenyc@ab.edu; Tel.: +1-304-457-6277
}

Received: 15 April 2018; Accepted: 4 May 2018; Published: 5 May 2018

check for updates

\begin{abstract}
Kaempferol is a widely distributed dietary flavonoid. Epidemiological studies have demonstrated kaempferol consumption lowers the risk of ovarian cancer. Our previous research proved that kaempferol suppresses human ovarian cancer cells by inhibiting tumor angiogenesis. However, the effects of kaempferol on the cell cycle and extrinsic apoptosis of ovarian cancer cells have not yet been studied. In the present study, we demonstrated that kaempferol induced G2/M cell cycle arrest via the Chk2/Cdc25C/Cdc2 pathway and Chk2/p21/Cdc2 pathway in human ovarian cancer A2780/CP70 cells. Chk2 was not responsible for kaempferol-induced apoptosis and up-regulation of p53. Kaempferol stimulated extrinsic apoptosis via death receptors/FADD/Caspase-8 pathway. Our study suggested that Chk2 and death receptors played important roles in the anticancer activity of kaempferol in A2780/CP70 cells. These findings provide more evidence of the anti-ovarian cancer properties of kaempferol and suggest that kaempferol could be a potential candidate for ovarian cancer adjuvant therapy.
\end{abstract}

Keywords: kaempferol; cell cycle arrest; Chk2; apoptosis; DR5; Fas

\section{Introduction}

Kaempferol (Figure 1A) is a widely distributed natural flavonoid. It occurs not only in various fruits and vegetables (e.g., apples, berries, broccoli), but also in many traditional medical herbs (e.g., Kaempferia rotunda L., Hedyotis diffusa Willd, Hypericum perforatum). Numerous studies have demonstrated that kaempferol and some kinds of kaempferol glycosides exert a wide range of physiological activities, including antioxidant, anti-inflammatory, anti-microbial, anticancer, anti-diabetic, and anti-obesity activities [1].

Recently, an epidemiological study has shown that kaempferol consumption is associated with a linear decline in ovarian cancer risk [2]. Ovarian cancer is a gynecological cancer with poor prognosis. The estimated new ovarian cancer cases and deaths in the United States in 2018 are 22,240 and 14,070, respectively [3]. Most ovarian cancer patients die because of delayed diagnosis or recurrent disease [4]. Cytoreductive surgery with chemotherapy is the standard of care for ovarian cancer. However, the present treatment rarely works in patients with advanced-stage or recurrent ovarian cancer, and may cause severe systemic toxicity [5]. Therefore, it is essential to develop more efficient and safer cancer treatments. Flavonoids, a class of plant secondary metabolites, are regarded as prospective 
compounds for cancer prevention and anticancer therapy because of their high effectiveness and few side effects [6,7]. Checkpoint kinase 2 (Chk2) and death receptors have been reported to be the targets of flavonoids [8-11].

Chk2, a stable serine/threonine kinase expressed throughout the cell cycle, is a tumor suppressor which regulates multiple fundamental cellular functions [12]. Mutations and/or deletions of Chk2 have been linked to a wide range of cancers [12]. Chk2 can be phosphorylated at threonine 68 and activated in response to DNA damage [13]. Active Chk2 acts as a signal transducer and phosphorylates a variety of substrates, such as the Cdc25 phosphatases, p53 and E2F1, which are associated with the induction of the cell cycle arrest, the initiation of DNA repair, and the activation of apoptosis [14].

Death receptors are members of the tumor necrosis factor receptor superfamily characterized by a cytoplasmic region known as the "death domain" [15]. DR5 (also known as TRAILR2) and Fas (also known as CD95) belong to the death receptor family. The binding of death receptors with their corresponding ligands results in the transduction of apoptotic and/or survival signals. For DR5 and Fas, they only activate apoptotic pathways [16]. Up-regulation of death receptors is not only a common strategy shared by many chemotherapy drugs to induce apoptosis of cancer cells $[17,18]$, but also is related to overcoming drug resistance of cancer cells [19,20].

Our previous research revealed that kaempferol induced human ovarian cancer cells through activating the p53 pathway [21] and decreasing angiogenesis through ERK-NFKB-cMyc-p21 pathway [22]. In this study, we investigated whether kaempferol could interrupt the cell cycle and trigger extrinsic apoptosis in human ovarian cancer A2780/CP70 cells. The possible underlying mechanisms were also explored.

\section{Results}

\subsection{Kaempferol Inhibits the Viability of A2780/CP70 Cells}

To assess cell viability, the CellTiter $96^{\circledR}$ Aqueous One Solution Cell Proliferation Assay was performed. Kaempferol dose-dependently inhibited the viability of human ovarian cancer A2780/CP70 cells. When treated with $40 \mu \mathrm{M}$ kaempferol for $48 \mathrm{~h}$, the viability of A2780/CP70 cells was reduced to $59 \%$ (Figure 1B). Meanwhile, kaempferol elicited less cytotoxicity to human normal ovarian epithelial IOSE 364 cells (Figure 1B).

A<smiles>O=c1c(O)c(-c2ccc(O)cc2)oc2cc(O)cc(O)c12</smiles>

B

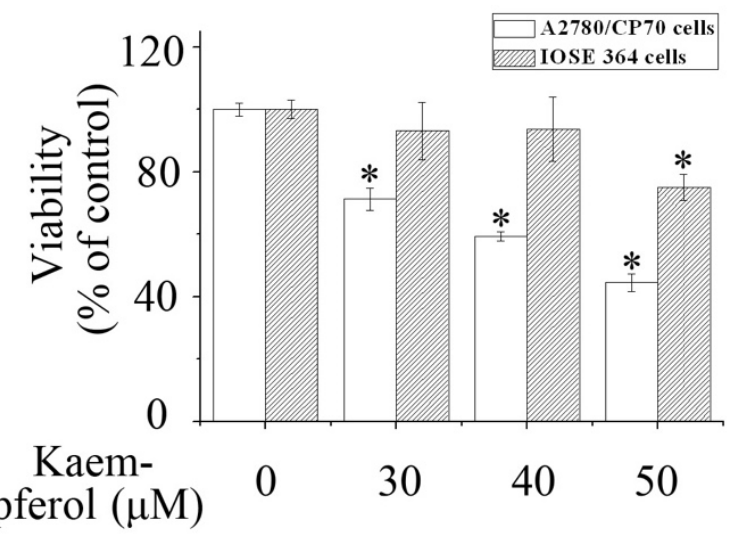

Figure 1. Kaempferol preferentially inhibited the viability of human ovarian carcinoma A2780/CP70 cells. (A) Chemical structure of kaempferol; (B) The effects of keampferol on the viability of A2780/CP70 cells and IOSE-364 cells. ${ }^{*} \mathrm{P}<0.05$ compared with the control group.

\subsection{Kaempferol Induces G2/M Cell Cycle Arrest in A2780/CP70 Cells}

To measure the cell cycle distribution of A2780/CP70 cells after kaempferol treatment, cells were stained by PI and analyzed using flow cytometry. Cell cycle analysis revealed that kaempferol 
effectively induced an increased population of cells in the G2/M phase, suggesting kaempferol led to G2/M cell cycle arrest in A2780/CP70 cells (Figure 2A,B).

\section{A}
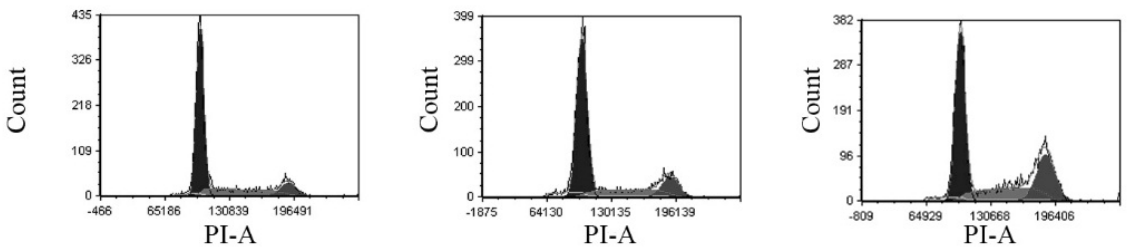

Kaempferol $(\mu \mathrm{M})$

30

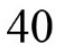

$\mathrm{B}$

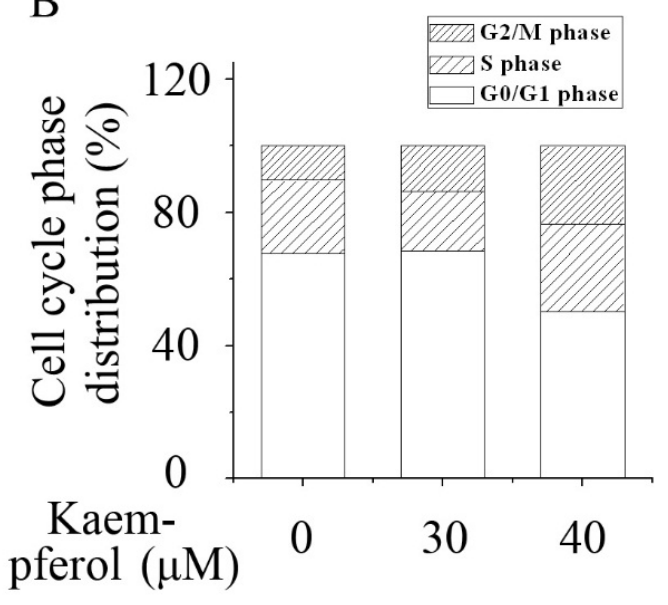

$\mathrm{C}$

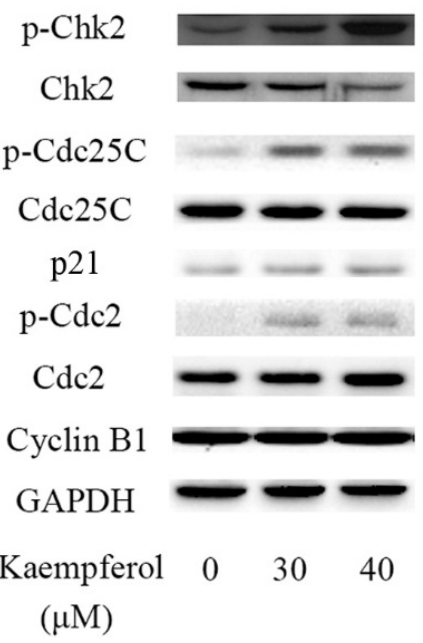

$\mathrm{D}$

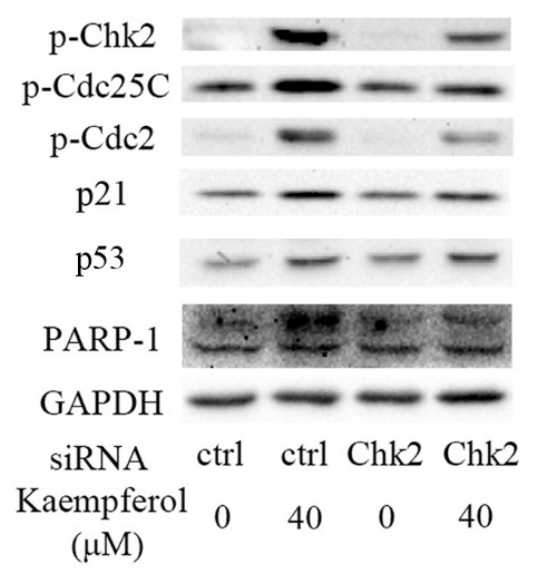

Figure 2. Kaempferol induced G2/M cell cycle arrest in A2780/CP70 cells via Chk2. (A,B) Flow cytometry assays revealed that kaempferol induced G2/M cell cycle arrest in A2780/CP70 cells; (C) Kaempferol increased the expression of p-Chk2, p-Cdc25C, p21 and p-Cdc2, but had no influence on the expression of Cyclin B1 in A2780/CP70 cells; (D) Knockdown of Chk2 attenuated kaempferol-induced up-regulation of p-Chk2, p-Cdc25C, p21 and p-Cdc2, but had no effect on the expression of p53 and cleavage of PARP-1 in A2780/CP70 cells. Glyceraldehyde-3-phosphate dehydrogenase (GAPDH) served as the loading control. Ctrl is short for control. 


\subsection{Kaempferol Induces Cell Cycle Arrest via Chk2}

The cell cycle is driven by cyclin dependent kinases (CDKs) that associate with cyclin regulatory proteins at different points of the cell cycle. The activity of the Cyclin B1-Cdc2 complex is pivotal in the G2/M transition. Cdc2 is activated via dephosphorylating at Tyr15 and Thr14 during progression into mitosis. Cdc25C, which can be phosphorylated at Ser216 and inactivated by active Chk2, is a protein phosphatase responsible for activating Cdc2. P21, which can be induced by activation of Chk2 in a p53-independent manner [23], is another regulator of Cdc2 [24].

Western blot analysis demonstrated that the expression of p21 and the phosphorylation of Chk2, Cdc25C, and Cdc2 were dramatically enhanced after kaempferol treatment in A2780/CP70 cells (Figure 2C). The expression of Cyclin B1 was not influenced by kaempferol (Figure 2C). These results implied that kaempferol might induce G2/M cell cycle arrest by up-regulating the expression of p21 and inactivating G2/M phase-related proteins Cdc25C and Cdc2 through activating Chk2.

To explore the role of Chk2 in kaempferol-mediated G2/M cell cycle arrest in A2780/CP70 cells, Chk2 siRNA was transfected into A2780/CP70 cells to block the expression of Chk2. Knockdown of Chk2 partially abrogated kaempferol-induced up-regulation of p-Chk2, p-Cdc25C, p21 and p-Cdc2 (Figure 2D). The result indicated that kaempferol halted the cell cycle progression at G2/M phase via the Chk2/ Cdc25C/ Cdc2 pathway and Chk2/ p21/ Cdc2 pathway in A2780/CP70 cells.

\subsection{Kaempferol Stimulates Apoptosis in A2780/CP70 Cells}

Apoptosis is a form of programmed cell death [25]. The intrinsic (mitochondria-mediated) and extrinsic (receptor-mediated) pathways are two major apoptotic pathways. Caspase- 8 and Caspase- 9 are key initial caspases in the extrinsic apoptotic pathway and intrinsic apoptotic pathway, respectively. Activation of initial caspases leads to activation of effector caspases (e.g., Caspase-3 and Caspase-7) and cleavage of PARP-1.

The result of flow cytometry assays revealed that kaempferol induced apoptosis in A2780/CP70 cells. The late apoptotic rate of A2780/CP70 cells was significantly increased to $23.95 \%$ when treated with $40 \mu \mathrm{M}$ kaempferol for $48 \mathrm{~h}$ (Figure 3A,B). In accordance with the result of the flow cytometry assays, kaempferol significantly enhanced the cleavage of PARP-1 and the activity of Caspase-3/7, -8 and -9 , respectively (Figure $3 \mathrm{C}$ ). These results suggested that kaempferol induced apoptosis in A2780/CP70 cells via intrinsic and extrinsic pathways.

A
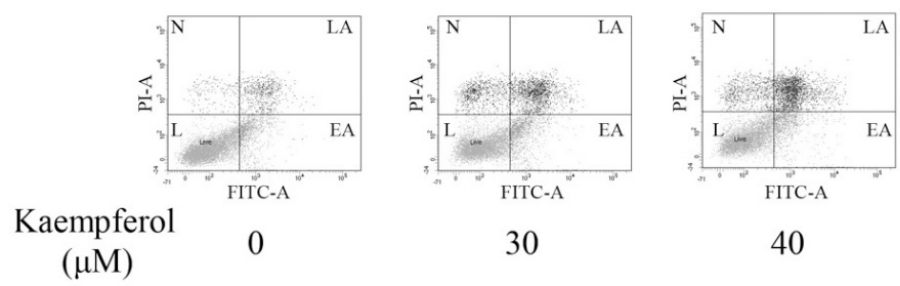

30

40

B

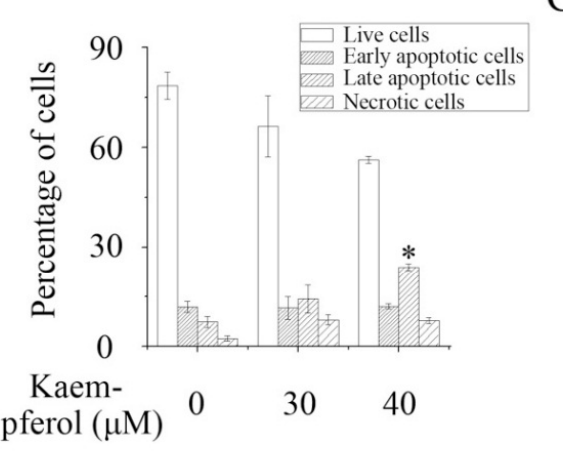

C

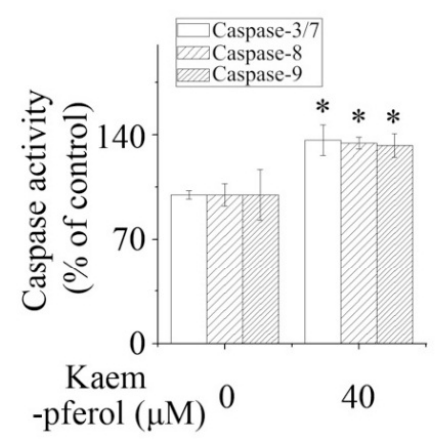

Figure 3. Cont. 
$\mathrm{D}$ DR5 (40kD)

Fas

FADD

PARP-1

GAPDH

Kaempferol $(\mu \mathrm{M})$
E

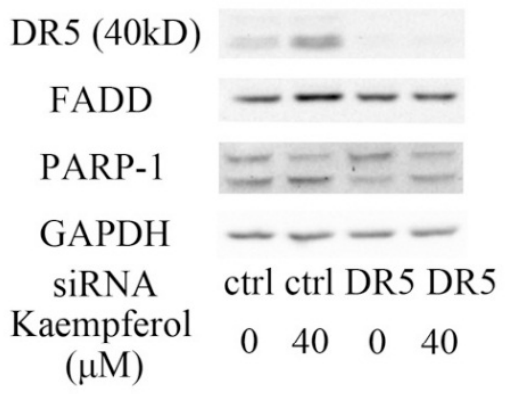

$\mathrm{F}$

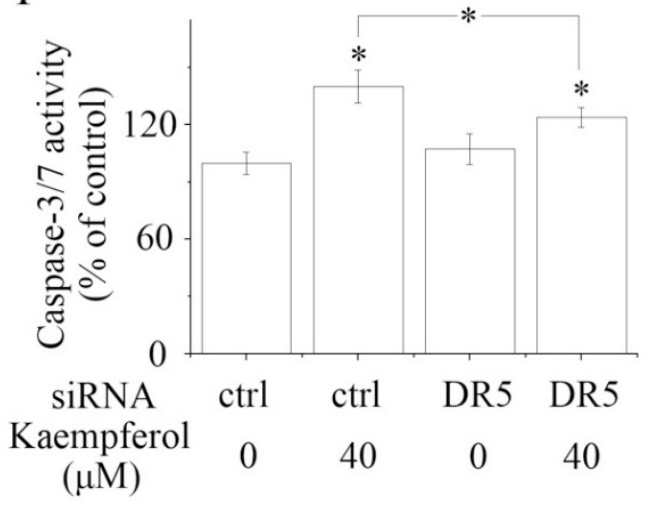

G

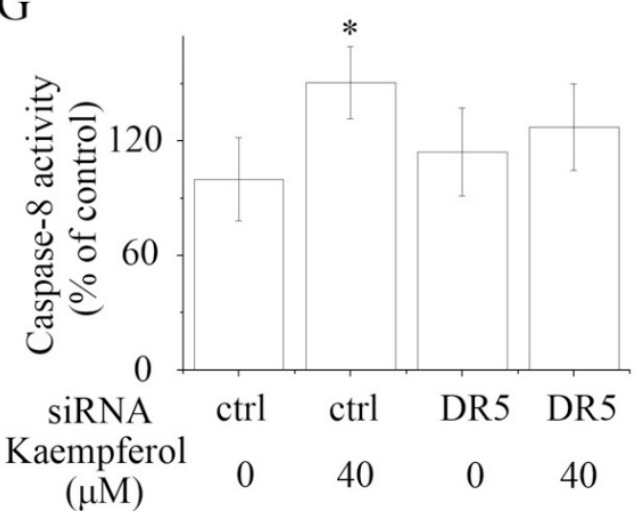

Figure 3. Kaempferol activated apoptosis in A2780/CP70 cells. (A,B) Flow Cytometry assays demonstrated that kaempferol induced apoptosis (mainly late apoptosis) in A2780/CP70 cells. N, LA, L and EA are short for necrotic cells, late apoptotic cells, living cells, and early apoptotic cells. (C) Kaempferol enhanced the activity of Caspase-3/7, -8 and -9 in A2780/CP70 cells. (D) Kaempferol promoted the expression of Fas, DR5, FADD, and cleaved PARP-1 in A2780/CP70 cells. (E-G) Knockdown of DR5 attenuated kaempferol-induced up-regulation of DR5, FADD and cleaved PARP-1, as well as the activation of Caspase-3/7 and Caspase-8. GAPDH served as the loading control. ${ }^{*} \mathrm{P}<0.05$ compared with control or between specific groups. Ctrl is short for control.

\subsection{Kaempferol Initiates Apoptosis Not via Chk2 but via Death Receptors}

It has been demonstrated that Chk2 can promote apoptosis in a p53-dependent manner. In the p53-dependent pathway, activated Chk2 mediates apoptosis through stabilizing and stimulating p53 [26,27]. Our previous work showed that kaempferol could induce intrinsic apoptosis via p53 [21]. To study whether Chk2 was involved in kaempferol-induced apoptosis, A2780/CP70 cells were transfected with Chk2 siRNA. Western blot analysis revealed that kaempferol-induced upregulation of p53 and cleavage of PARP-1 was not influenced by the knockdown of Chk2 (Figure 2D), suggesting that Chk2 was not involved in the kaempferol-induced apoptosis of A2780/CP70 cells and that kaempferol modulated the expression of p53 independently of Chk2.

As kaempferol enhanced the activity of Caspase-8, a key caspase in the extrinsic apoptotic pathway, we hypothesized that kaempferol might have an impact on the expression of death receptors and adaptor proteins. Western blot analysis showed that kaempferol increased the expression of two death receptors, DR5 and Fas, and one adaptor protein, FADD (Figure 3D). Blocking DR5 partially reversed kaempferol-induced up-regulation of the expression of FADD and activation of Caspase-3/7 and Caspase-8 (Figure 3E-G). Our data illustrated that kaempferol mediated apoptosis via death receptors/ FADD/ Caspase-8 pathway in A2780/CP70 cells. 


\subsection{Kaempferol Inhibits Ovarian Cancer OVCAR-3 Cells}

To explore whether the anti-ovarian cancer activities of kaempferol were universal, we tested the inhibitory effects of kaempferol on another ovarian cancer cell line OVCAR-3. Results showed that the viability of OVCAR-3 cells was reduced to $60 \%$ under the treatment of $40 \mu \mathrm{M}$ kaempferol for $48 \mathrm{~h}$ (Figure 4A).
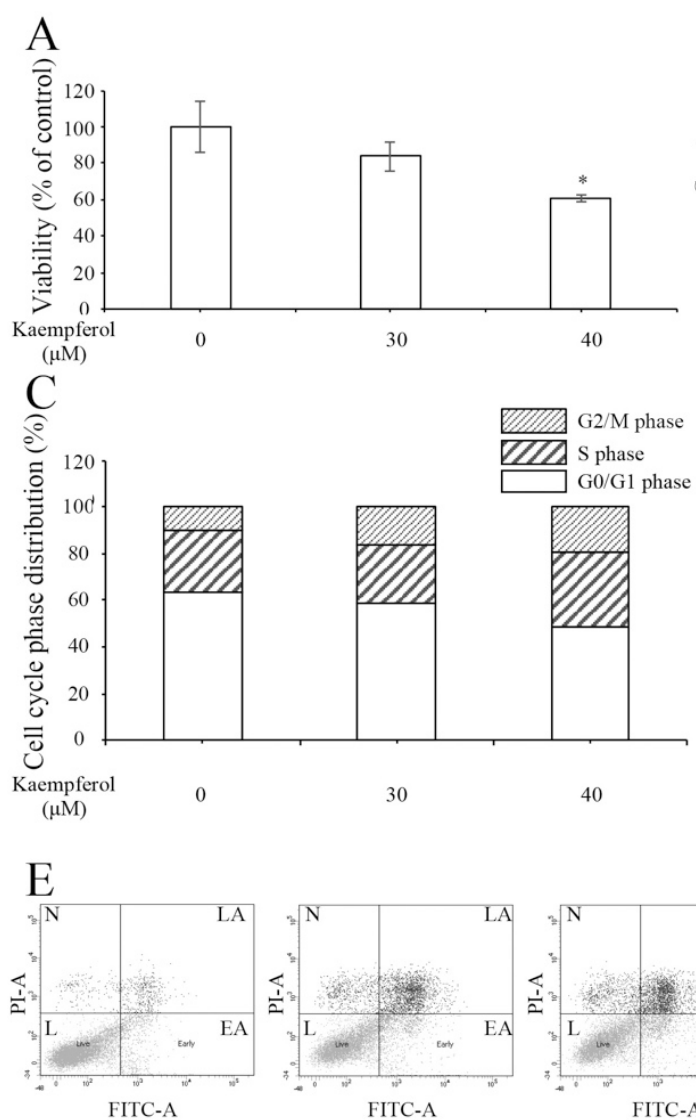

Kaempferol $\quad 0$

$(\mu \mathrm{M})$

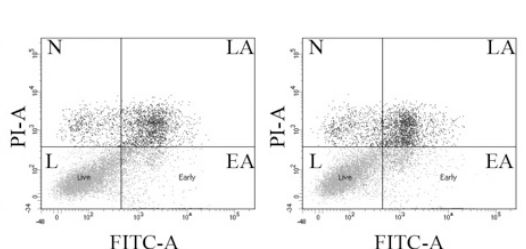

30

40

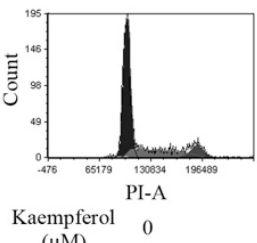

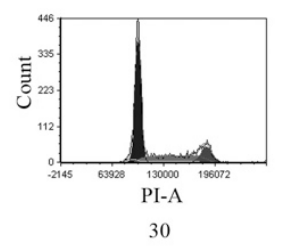

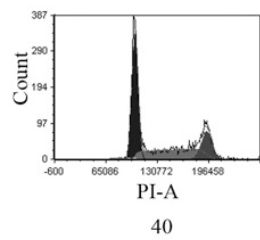

$\mathrm{D}$

$\mathrm{B}$

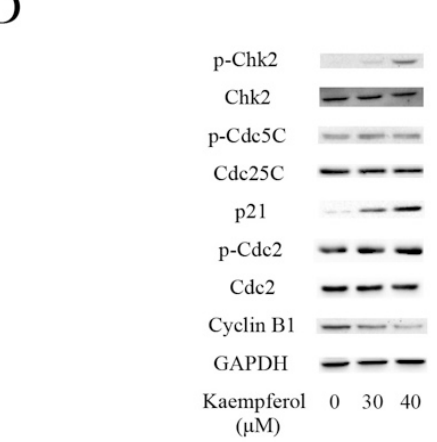

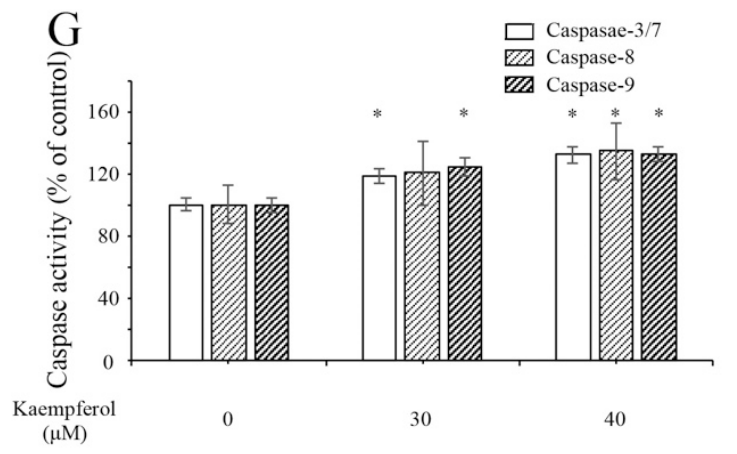

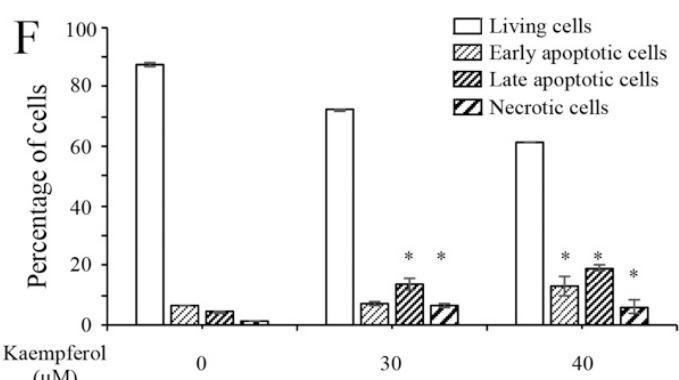

$\mathrm{H}$

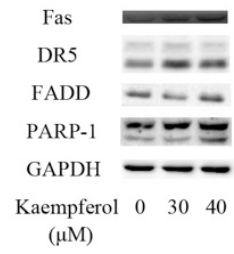

Figure 4. Anticancer activities of kaempferol on OVCAR-3 cells. (A) The effects of keampferol on the viability of OVCAR-3 cells. ${ }^{*} \mathrm{P}<0.05$ compared with the control group. (B,C) Flow cytometry assay revealed that kaempferol induced G2/M cell cycle arrest in OVCAR-3 cells. (D) Kaempferol influenced the expression of cell cycle-related proteins in OVCAR-3 cells. (E,F) Flow Cytometry assay presented that kaempferol induced apoptosis in OVCAR-3 cells. N, LA, L, and EA are short for necrotic cells, late apoptotic cells, living cells and early apoptotic cells. (G) Kaempferol enhanced the activity of Caspase-3/7, -8 and -9 in OVCAR-3 cells. (H) Kaempferol promoted the expression of Fas, DR5, and cleaved PARP-1 in OVCAR-3 cells. 
Kaempferol induced G2/M cell cycle arrest in a dose-dependent manner in OVCAR-3 cells (Figure 4B,C). Western blot assay revealed that kaempferol elevated the expression of p21 and activated the phosphorylation of Chk2, Cdc25C, and Cdc2 (Figure 4D). Meanwhile, it lowered the expression of Cyclin B1.

Kaempferol triggered apoptosis in OVCAR-3 cells. The results of flow cytometry illustrated that the percentages of early apoptotic cells and late apoptotic cells were significantly increased in kaempferol-treated cells (Figure 4E,F), respectively. Kaempferol lifted the activities of caspases (Figure 4G). Kaempferol increased the expression of Fas, DR5, and cleaved PARP-1 (Figure 4H).

In general, kaempferol had a suppressive effect on OVCAR-3 cells. The main mechanisms were similar to the mechanisms of kaempferol on A2780/CP70 cells.

\section{Discussion}

Despite the improvement in diagnosis and treatment, cancer is still one of the most fatal diseases. Surgery, chemotherapy, and radiation therapy are three standard types of cancer treatment. Recently, hormonal therapy and targeted therapy have been used to treat various cancers. However, current cancer therapies have drawbacks. The traditional therapies might cause severe adverse side effects in patients. The newly developed therapies can only be applied to treat certain types of cancer. Thus, it's necessary to find novel treatments or adjuvant therapies for treating cancer.

Flavonoids are regarded as promising anticancer agents. Some dietary flavonoids have cytotoxicity against various cancers, but have little or no side effects on normal cells. Kaempferol, a dietary flavonoid widely existing in vegetables and fruits, has anticancer activity. Our previous studies showed that kaempferol induced intrinsic apoptosis via activating p53 [21]. P53 is a major tumor suppressor whose function is critical for anticancer effects. However, loss and/or mutation of p53 is very common in human cancers [28]. Thus, we explored whether kaempferol had anticancer targets other than p53.

Chk2 emerges as an important signal transducer of cellular responses and a candidate tumor suppressor [29]. Activation of Chk2 leads to the phosphorylation of over 20 proteins. Cell cycle arrest, apoptosis, senescence, and DNA repair or tolerance of damage are induced by activation of Chk2 depending on the extent of damage, the cell type, and other factors [30].

$\mathrm{Cdc} 25 \mathrm{C}$ and $\mathrm{p} 21$ are two down-stream proteins of Chk2. Both of them regulate the activity of Cdc2. Some flavonoids and isoflavones exert anticancer activities by targeting these proteins. Eupatilin, a naturally occurring flavonoid isolated from Artemisia princeps, has been reported to inhibit the growth of human endometrial cancer cells via activating the Chk2/Cdc25C/Cdc2 pathway [8]. Dihydromyricetin, a flavonoid commonly found in grapes, berries, vegetables, herbs, and other plants, induces G2/M phase cell cycle arrest of hepatocellular carcinoma cells through the Chk2/Cdc25C pathway [31]. Genistein, an isoflavone found in soybeans and other plants, caused G2/M cell cycle arrest in MCF-7 and MDA-MB-231 breast carcinoma cells via p21-mediated inhibition of Cdc2 [32]. In the present study, we observed that kaempferol induced G2/M cell cycle arrest via the Chk2/Cdc25C/Cdc2 pathway and Chk2/p21/Cdc2 pathway in A2780/CP70 cells. This result is in accordance with a previous study. In that case, kaempferol was proven to activate G2 cell cycle arrest through the Chk1/Chk2 pathway in human acute leukemia Jurkat T cells [33]. Our study and previous studies implied that Chk2 might be a universal target for the cell cycle-interrupting activity of flavonoids.

Death receptors refer to those members of the tumor necrosis factor receptor superfamily that contain a death domain, such as Fas, DR4, and DR5. Among them, DR5 is regarded as one of the most important anticancer targets. Up-regulation and/or activation of DR5 not only sensitizes cancer cells to apoptosis [34,35], but also collapses tumor blood vessels to reduce tumor growth [36]. Recently, DR5 was proven to act as a suppressor of human cancer cell invasion and metastasis [37]. Many studies have shown that DR5 inducers or agonists exert anticancer activities in cell models and animal models. Synergistic anticancer effects are also detected when DR5 inducers or agonists are combined with traditional chemotherapeutics (e.g., doxorubicin) [38]. Unlike other death receptors, the expression of 
DR5 is much lower in normal tissues than in cancerous tissues [36,39], implying that targeting DR5 might induce cancer-specific cell death and cause few adverse effects in normal cells. In the present study, kaempferol enhanced the expression of DR5, Fas, and FADD, the activity of Caspase-8 and cleavage of PARP-1. Knockdown of DR5 partially rescued kaemferol-induced activation of the extrinsic apoptotic pathway. Former studies illustrated that kaempferol increased the levels of membrane-bound FAS ligand, decreased uncleaved caspase- 8 and intact Bid, and increased caspase- 8 activity in HT-29 human colon cancer cells [40]. In human colon cancer SW480 cells, kaempferol markedly up-regulated tumor necrosis factor-related apoptosis-inducing ligand (TRAIL) receptors, DR5, and death receptor 4 (DR4) [41]. Kaempferol sensitized cancer cells to TRAIL-induced apoptosis via up-regulation of death receptors [41]. One of the mechanisms in which kaempferol modulated death receptors was by activating the reactive oxygen species-mediated p53/ ataxia telangiectasia mutated (ATM) signaling pathway [42]. Another study indicated that the JNK/ ERK-CHOP pathway was also involved [43]. Our results supplied additional evidence that death receptor signaling pathway played an important role in kaempferol-induced apoptosis.

\section{Materials and Methods}

\subsection{Cell Culture and Reagents}

Human ovarian carcinoma cell lines A2780/CP70 and human immortalized ovarian surface epithelial cells (IOSE 364), were kind gifts from Dr. Bing-Hua Jiang at Thomas Jefferson University and Dr. Auersperg at the University of British Columbia, respectively. Cells were cultured in RPMI 1640 medium (Sigma, St. Louis, MO, USA) incorporating 10\% fetal bovine serum (FBS) (Invitrogen, Grand Island, NY, USA). Cells were grown in a humidified incubator containing $5 \% \mathrm{CO}_{2}$ at $37{ }^{\circ} \mathrm{C}$.

Reagents: Kaempferol was purchased from Sigma. Dead Cell Apoptosis Kit with Annexin V Alexa Fluor $^{\circledR} 488$ and propidium iodide (PI) was purchased from ThermoFisher Scientific (Waltham, MA, USA). Caspase-Glo ${ }^{\circledR}$ 3/7 Assay Systems, Caspase-Glo ${ }^{\circledR} 8$ Assay Systems and Caspase-Glo ${ }^{\circledR} 9$ Assay Systems were purchased from Promega (Madison, WI, USA). Antibodies against p21 Waf1/Cip1 (p21), p-Cdc25C (Ser 216), Cdc25C, p-Cdc2 (Tyr 15), Cdc2, Cyclin B1, p53, death receptor 5 (DR5), Fas, and Fas-Associated protein with Death Domain (FADD) were purchased from Cell Signaling Technology, Inc. (Danvers, MA, USA). Antibodies against phosphor-checkpoint kinase 2 (Chk2) (Thr68), Chk2, poly [ADP-ribose] polymerase 1 (PARP-1), and glyceraldehyde-3-phosphate dehydrogenase (GAPDH) were purchased from Santa Cruz Biotechnology Inc. (Santa Cruz, CA, USA).

\subsection{Assessment of Cell Viability In Vitro}

Cells were seeded into 96-well plates at a density of $10^{4}$ cells per well in medium with $10 \%$ FBS. After overnight growth, cells were treated with kaempferol for $48 \mathrm{~h}$. Cell viability was measured using the CellTiter $96^{\circledR}$ Aqueous One Solution Cell Proliferation Assay (Promega, Madison, WI, USA), according to the manufacturer's instructions. Cell viability was expressed as a percentage compared to the control group.

\subsection{Cell Cycle Analysis}

Cells were treated with kaempferol for $48 \mathrm{~h}$. Then cells were harvested and fixed with cold $70 \%$ ethanol overnight. Cells were stained according to the manufacturer's instructions. Data acquisition and analysis were performed following flow cytometry with accompanying software (FACS Calibur, version 5.1, BD Bioscience, San Jose, CA, USA).

\subsection{Western Blot}

Cells were treated with kaempferol for $48 \mathrm{~h}$ in $60 \mathrm{~mm}$ dishes and then harvested. The Western blot assay was conducted according to a previously published method [44]. Protein bands were quantified with the NIH ImageJ software (NIH), normalized to the corresponding GAPDH band for analysis. 


\subsection{Transfection with Small Interfering RNA (siRNA)}

Cells were seeded and incubated overnight. Then cells were transfected with control or target-specific siRNA using jetPRIME ${ }^{\mathrm{TM}} \mathrm{DNA}$ and siRNA transfection reagent (VWR International, Radnor, PA, USA) according to the manufacturer's protocol. After $24 \mathrm{~h}$, cells were exposed to cell culture medium containing kaempferol ( 0 or $40 \mu \mathrm{mol} / \mathrm{L})$ for another $48 \mathrm{~h}$.

\subsection{Apoptosis Analysis}

Cells were treated with kaempferol for $48 \mathrm{~h}$. Then cells were collected and stained with Annexin V Alexa Fluor ${ }^{\circledR} 488$ and propidium iodide (PI) according to the manufacturer's instructions. Data acquisition and analysis were performed following flow cytometry with accompanying software (FACS Calibur; BD Bioscience, San Jose, CA, USA).

\subsection{Caspase Activity Assay}

Cells were seeded into 96-well plates at a density of $10^{4}$ cells per well in medium with $10 \%$ FBS. After overnight growth, cells were treated with kaempferol for $48 \mathrm{~h}$. Caspase-3/7, Caspase-8, and Caspase- 9 activities were detected using Caspase-Glo 3/7, Caspase-Glo 8 or Caspase-Glo 9 Assay kit (Promega), respectively. Caspase activities were expressed as a percentage compared to the control group.

\subsection{Statistical Analysis}

All data were expressed as mean \pm standard error of mean (SEM) from at least three independent experiments. The results were analyzed with SPSS Version 18.0 for Windows (SPSS, Chicago, IL, USA) using one-way analysis of variance (ANOVA) and a post hoc test (2-sided Dunnett's test) to test both overall differences and specific differences between each treatment and control. P values $<0.05$ were considered statistically significant.

\section{Conclusions}

Taken together, Chk2 and death receptors are pivotal anticancer targets of kaempferol (Figure 5). Kaempferol induced G2/M cell cycle arrest via the Chk2/Cdc25C/Cdc2 pathway and Chk2/p21/Cdc2 pathway. Chk2 was not involved in kaempferol-induced apoptosis. Kaempferol mediated intrinsic apoptosis via p53 in a Chk2-independent manner. It increased the expression of DR5 and Fas, resulting in the activation of extrinsic apoptosis. Since A2780/CP70 cells are cisplatin-resistant, our results suggested that kaempferol might help overcome cisplatin resistance in ovarian cancer. More studies are required to verify this hypothesis.

$$
\underset{(\text { DR5, Fas })}{\text { Death receptors }} \rightarrow \text { Caspase- } 8 \rightarrow \text { Caspase-3/7 } \rightarrow \text { PARP- } 1 \rightarrow \text { Apoptosis }
$$

\section{Kaempferol}

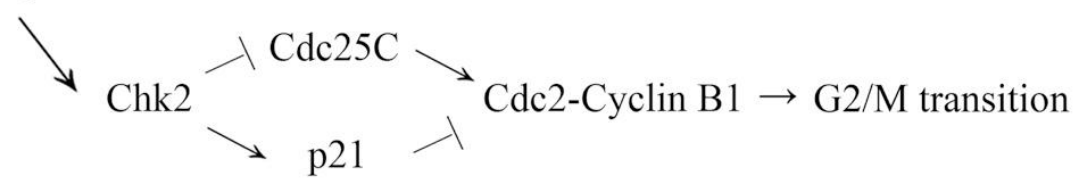

Figure 5. Proposed mechanism of inhibition of A2780/CP70 cells via Chk2 and death receptor signaling pathways.

Author Contributions: Y.G., J.Y., G.O.R., and Y.C.C. conceived and designed the experiments; Y.G. performed the experiments; Y.G. analyzed the data; Y.C.C. contributed reagents/materials/analysis tools; Y.G., J.Y., G.O.R., and Y.C.C. wrote the paper.

Acknowledgments: The authors thank Kathy Brundage from the Flow Cytometry Core at the West Virginia University for providing technical help on cell cycle analysis. This research was supported by NIH grants 
P20RR016477 from the National Center for Research Resources and P20GM103434 from the National Institute for General Medical Sciences (NIGMS) awarded to the West Virginia IDeA Network of Biomedical Research Excellence. This research was supported by Grant Number P20GM104932 from NIGMS, a component of the National Institutes of Health $(\mathrm{NIH})$ and its contents are solely the responsibility of the authors and do not necessarily represent the official view of NIGMS or NIH. This study was also supported by COBRE grant GM102488/RR032138, ARIA S10 grant RR020866, FORTESSA S10 grant OD016165, and INBRE grant GM103434. This research was also supported by China Postdoctoral Science Foundation Grant No. 2017M611065 and Zhejiang Province Postdoctoral Science Grant.

Conflicts of Interest: The authors declare no conflict of interest. The funding sponsors had no role in the design of the study; in the collection, analyses, or interpretation of data; in the writing of the manuscript, or in the decision to publish the results.

\section{References}

1. Calderon-Montano, J.M.; Burgos-Moron, E.; Perez-Guerrero, C.; Lopez-Lazaro, M. A review on the dietary flavonoid kaempferol. Mini. Rev. Med. Chem. 2011, 11, 298-344. [CrossRef] [PubMed]

2. Gates, M.A.; Tworoger, S.S.; Hecht, J.L.; De Vivo, I.; Rosner, B.; Hankinson, S.E. A prospective study of dietary flavonoid intake and incidence of epithelial ovarian cancer. Int. J Cancer 2007, 121, 2225-2232. [CrossRef] [PubMed]

3. Siegel, R.L.; Miller, K.D.; Jemal, A. Cancer statistics, 2018. CA Cancer J. Clin. 2018, 68, 7-30. [CrossRef] [PubMed]

4. Mizuno, T.; Suzuki, N.; Makino, H.; Furui, T.; Morii, E.; Aoki, H.; Kunisada, T.; Yano, M.; Kuji, S.; Hirashima, Y.; et al. Cancer stem-like cells of ovarian clear cell carcinoma are enriched in the aldh-high population associated with an accelerated scavenging system in reactive oxygen species. Gynecol. Oncol. 2015, 137, 299-305. [CrossRef] [PubMed]

5. Kao, Y.L.; Kuo, Y.M.; Lee, Y.R.; Yang, S.F.; Chen, W.R.; Lee, H.J. Apple polyphenol induces cell apoptosis, cell cycle arrest at $\mathrm{g} 2 / \mathrm{m}$ phase, and mitotic catastrophe in human bladder transitional carcinoma cells. J. Funct. Foods 2015, 14, 384-394. [CrossRef]

6. Ravishankar, D.; Rajora, A.K.; Greco, F.; Osborn, H.M. Flavonoids as prospective compounds for anti-cancer therapy. Int. J. Biochem. Cell Biol. 2013, 45, 2821-2831. [CrossRef] [PubMed]

7. Romagnolo, D.F.; Selmin, O.I. Flavonoids and cancer prevention: A review of the evidence. J. Nutr. Gerontol. Geriatr. 2012, 31, 206-238. [CrossRef] [PubMed]

8. Cho, J.H.; Lee, J.G.; Yang, Y.I.; Kim, J.H.; Ahn, J.H.; Baek, N.I.; Lee, K.T.; Choi, J.H. Eupatilin, a dietary flavonoid, induces $\mathrm{g} 2 / \mathrm{m}$ cell cycle arrest in human endometrial cancer cells. Food Chem. Toxicol. 2011, 49, 1737-1744. [CrossRef] [PubMed]

9. Hsu, Y.L.; Uen, Y.H.; Chen, Y.; Liang, H.L.; Kuo, P.L. Tricetin, a dietary flavonoid, inhibits proliferation of human breast adenocarcinoma mcf-7 cells by blocking cell cycle progression and inducing apoptosis. J. Agric. Food Chem. 2009, 57, 8688-8695. [CrossRef] [PubMed]

10. Hung, J.Y.; Hsu, Y.L.; Ko, Y.C.; Tsai, Y.M.; Yang, C.J.; Huang, M.S.; Kuo, P.L. Didymin, a dietary flavonoid glycoside from citrus fruits, induces fas-mediated apoptotic pathway in human non-small-cell lung cancer cells in vitro and in vivo. Lung Cancer 2010, 68, 366-374. [CrossRef] [PubMed]

11. Horinaka, M.; Yoshida, T.; Shiraishi, T.; Nakata, S.; Wakada, M.; Nakanishi, R.; Nishino, H.; Matsui, H.; Sakai, T. Luteolin induces apoptosis via death receptor 5 upregulation in human malignant tumor cells. Oncogene 2005, 24, 7180-7189. [CrossRef] [PubMed]

12. Bartek, J.; Lukas, J. Chk1 and chk2 kinases in checkpoint control and cancer. Cancer Cell 2003, 3, 421-429. [CrossRef]

13. Hirao, A.; Cheung, A.; Duncan, G.; Girard, P.M.; Elia, A.J.; Wakeham, A.; Okada, H.; Sarkissian, T.; Wong, J.A.; Sakai, T.; et al. Chk2 is a tumor suppressor that regulates apoptosis in both an ataxia telangiectasia mutated (atm)-dependent and an atm-independent manner. Mol. Cell. Biol. 2002, 22, 6521-6532. [CrossRef] [PubMed]

14. Stolz, A.; Ertych, N.; Bastians, H. Tumor suppressor chk2: Regulator of DNA damage response and mediator of chromosomal stability. Clin. Cancer Res. 2011, 17, 401-405. [CrossRef] [PubMed]

15. Guicciardi, M.E.; Gores, G.J. Life and death by death receptors. FASEB J. 2009, 23, 1625-1637. [CrossRef] [PubMed]

16. Lavrik, I.; Golks, A.; Krammer, P.H. Death receptor signaling. J. Cell Sci. 2005, 118, 265-267. [CrossRef] [PubMed] 
17. Debatin, K.M.; Krammer, P.H. Death receptors in chemotherapy and cancer. Oncogene 2004, 23, $2950-2966$. [CrossRef] [PubMed]

18. Friesen, C.; Herr, I.; Krammer, P.H.; Debatin, K.M. Involvement of the cd95 (apo-1/fas) receptor/ligand system in drug-induced apoptosis in leukemia cells. Nat. Med. 1996, 2, 574-577. [CrossRef] [PubMed]

19. Parajuli, B.; Shin, S.J.; Kwon, S.H.; Cha, S.D.; Chung, R.; Park, W.J.; Lee, H.G.; Cho, C.H. Salinomycin induces apoptosis via death receptor-5 up-regulation in cisplatin-resistant ovarian cancer cells. Anticancer Res. 2013, 33, 1457-1462. [PubMed]

20. Shankar, S.; Ganapathy, S.; Chen, Q.; Srivastava, R.K. Curcumin sensitizes trail-resistant xenografts: Molecular mechanisms of apoptosis, metastasis and angiogenesis. Mol. Cancer 2008, 7, 16. [CrossRef] [PubMed]

21. Luo, H.; Rankin, G.O.; Li, Z.; Depriest, L.; Chen, Y.C. Kaempferol induces apoptosis in ovarian cancer cells through activating p53 in the intrinsic pathway. Food Chem. 2011, 128, 513-519. [CrossRef] [PubMed]

22. Luo, H.; Rankin, G.O.; Juliano, N.; Jiang, B.H.; Chen, Y.C. Kaempferol inhibits vegf expression and in vitro angiogenesis through a novel erk-nfkappab-cmyc-p21 pathway. Food Chem. 2012, 130, 321-328. [CrossRef] [PubMed]

23. Aliouat-Denis, C.M.; Dendouga, N.; van den Wyngaert, I.; Goehlmann, H.; Steller, U.; van de Weyer, I.; van Slycken, N.; Andries, L.; Kass, S.; Luyten, W.; et al. P53-independent regulation of p21waf1/cip1 expression and senescence by chk2. Mol. Cancer Res. 2005, 3, 627-634. [CrossRef] [PubMed]

24. Yu, D.; Jing, T.; Liu, B.; Yao, J.; Tan, M.; McDonnell, T.J.; Hung, M.C. Overexpression of erbb2 blocks taxol-induced apoptosis by upregulation of p21cip1, which inhibits p34cdc2 kinase. Mol. Cell 1998, 2, 581-591. [CrossRef]

25. Renehan, A.G.; Booth, C.; Potten, C.S. What is apoptosis, and why is it important? BMJ 2001, 322, $1536-1538$. [CrossRef] [PubMed]

26. Hirao, A.; Kong, Y.Y.; Matsuoka, S.; Wakeham, A.; Ruland, J.; Yoshida, H.; Liu, D.; Elledge, S.J.; Mak, T.W. DNA damage-induced activation of p53 by the checkpoint kinase chk2. Science 2000, 287, 1824-1827. [CrossRef] [PubMed]

27. Jack, M.T.; Woo, R.A.; Hirao, A.; Cheung, A.; Mak, T.W.; Lee, P.W. Chk2 is dispensable for p53-mediated g1 arrest but is required for a latent p53-mediated apoptotic response. Proc. Natl. Acad. Sci. USA 2002, 99, 9825-9829. [CrossRef] [PubMed]

28. Hollstein, M.; Sidransky, D.; Vogelstein, B.; Harris, C.C. P53 mutations in human cancers. Science 1991, 253, 49-53. [CrossRef] [PubMed]

29. Nevanlinna, H.; Bartek, J. The chek2 gene and inherited breast cancer susceptibility. Oncogene 2006, 25, 5912-5919. [CrossRef] [PubMed]

30. Zannini, L.; Delia, D.; Buscemi, G. Chk2 kinase in the DNA damage response and beyond. J. Mol. Cell Biol. 2014, 6, 442-457. [CrossRef] [PubMed]

31. Huang, H.; Hu, M.; Zhao, R.; Li, P.; Li, M. Dihydromyricetin suppresses the proliferation of hepatocellular carcinoma cells by inducing g2/m arrest through the chk1/chk2/cdc25c pathway. Oncol. Rep. 2013, 30, 2467-2475. [CrossRef] [PubMed]

32. Choi, Y.H.; Zhang, L.; Lee, W.H.; Park, K.Y. Genistein-induced g2/m arrest is associated with the inhibition of cyclin b1 and the induction of p21 in human breast carcinoma cells. Int. J. Oncol. 1998, 13, 391-396. [CrossRef] [PubMed]

33. Kim, K.Y.; Jang, W.Y.; Lee, J.Y.; Jun, D.Y.; Ko, J.Y.; Yun, Y.H.; Kim, Y.H. Kaempferol activates g(2)-checkpoint of the cell cycle resulting in $\mathrm{g}(2)$-arrest and mitochondria-dependent apoptosis in human acute leukemia jurkat t cells. J. Microbiol. Biotechnol. 2016, 26, 287-294. [CrossRef] [PubMed]

34. Camidge, D.R.; Herbst, R.S.; Gordon, M.S.; Eckhardt, S.G.; Kurzrock, R.; Durbin, B.; Ing, J.; Tohnya, T.M.; Sager, J.; Ashkenazi, A.; et al. A phase i safety and pharmacokinetic study of the death receptor 5 agonistic antibody pro95780 in patients with advanced malignancies. Clin. Cancer Res. 2010, 16, 1256-1263. [CrossRef] [PubMed]

35. LaVallee, T.M.; Zhan, X.H.; Johnson, M.S.; Herbstritt, C.J.; Swartz, G.; Williams, M.S.; Hembrough, W.A.; Green, S.J.; Pribluda, V.S. 2-methoxyestradiol up-regulates death receptor 5 and induces apoptosis through activation of the extrinsic pathway. Cancer Res. 2003, 63, 468-475. [PubMed] 
36. Wilson, N.S.; Yang, A.; Yang, B.; Couto, S.; Stern, H.; Gogineni, A.; Pitti, R.; Marsters, S.; Weimer, R.M.; Singh, M.; et al. Proapoptotic activation of death receptor 5 on tumor endothelial cells disrupts the vasculature and reduces tumor growth. Cancer Cell 2012, 22, 80-90. [CrossRef] [PubMed]

37. Oh, Y.T.; Yue, P.; Wang, D.; Tong, J.S.; Chen, Z.G.; Khuri, F.R.; Sun, S.Y. Suppression of death receptor 5 enhances cancer cell invasion and metastasis through activation of caspase-8/traf2-mediated signaling. Oncotarget 2015, 6, 41324-41338. [CrossRef] [PubMed]

38. Xu, L.H.; Deng, C.S.; Zhu, Y.Q.; Liu, S.Q.; Liu, D.Z. Synergistic antitumor effect of trail and doxorubicin on colon cancer cell line sw480. World J. Gastroenterol. 2003, 9, 1241-1245. [CrossRef] [PubMed]

39. Li, Y.; Fan, X.; Goodwin, C.R.; Laterra, J.; Xia, S. Hepatocyte growth factor enhances death receptor-induced apoptosis by up-regulating dr5. BMC Cancer 2008, 8, 325. [CrossRef] [PubMed]

40. Lee, H.S.; Cho, H.J.; Yu, R.; Lee, K.W.; Chun, H.S.; Park, J.H. Mechanisms underlying apoptosis-inducing effects of kaempferol in ht-29 human colon cancer cells. Int. J. Mol. Sci. 2014, 15, 2722-2737. [CrossRef] [PubMed]

41. Yoshida, T.; Konishi, M.; Horinaka, M.; Yasuda, T.; Goda, A.E.; Taniguchi, H.; Yano, K.; Wakada, M.; Sakai, T. Kaempferol sensitizes colon cancer cells to trail-induced apoptosis. Biochem. Biophys. Res. Commun. 2008, 375, 129-133. [CrossRef] [PubMed]

42. Lee, C.F.; Yang, J.S.; Tsai, F.J.; Chiang, N.N.; Lu, C.C.; Huang, Y.S.; Chen, C.; Chen, F.A. Kaempferol induces $\mathrm{atm} / \mathrm{p} 53-$ mediated death receptor and mitochondrial apoptosis in human umbilical vein endothelial cells. Int. J. Oncol. 2016, 48, 2007-2014. [CrossRef] [PubMed]

43. Zhao, Y.; Tian, B.; Wang, Y.; Ding, H. Kaempferol sensitizes human ovarian cancer cells-ovcar-3 and skov-3 to tumor necrosis factor-related apoptosis-inducing ligand (trail)-induced apoptosis via jnk/erk-chop pathway and up-regulation of death receptors 4 and 5. Med. Sci. Monit. 2017, 23, 5096-5105. [CrossRef] [PubMed]

44. Gao, Y.; Rankin, G.O.; Tu, Y.; Chen, Y.C. Theaflavin-3, 3'-digallate decreases human ovarian carcinoma ovcar-3 cell-induced angiogenesis via akt and notch-1 pathways, not via mapk pathways. Int. J. Oncol. 2016, 48, 281-292. [CrossRef] [PubMed]

Sample Availability: Kaempferol is available from the authors.

(C) 2018 by the authors. Licensee MDPI, Basel, Switzerland. This article is an open access article distributed under the terms and conditions of the Creative Commons Attribution (CC BY) license (http:/ / creativecommons.org/licenses/by/4.0/). 